\title{
REVIEW
}

\section{Diabetes Dyslipidemia}

Jonathan D. Schofield · Yifen Liu • Prasanna Rao-Balakrishna · Rayaz A. Malik •

Handrean Soran

Received: February 23, 2016/Published online: April 7, 2016

(C) The Author(s) 2016. This article is published with open access at Springerlink.com

\section{ABSTRACT}

Diabetes mellitus is associated with a considerably increased risk of premature atherosclerotic cardiovascular disease. Intensive glycemic control has essentially failed to significantly improve cardiovascular outcomes in clinical trials. Dyslipidemia is common in diabetes and there is strong evidence that cholesterol lowering improves cardiovascular outcomes, even in patients with apparently unremarkable lipid profiles. Here, the authors review the pathophysiology and implications of the alterations in lipoproteins observed in both type 1 and type 2 diabetes, the

Enhanced content To view enhanced content for this article go to http://www.medengine.com/Redeem/ 8D84F060667C559A.

J. D. Schofield · Y. Liu · R. A. Malik

Faculty of Medical and Human Sciences, Institute of Human Development, University of Manchester,

Manchester, UK

J. D. Schofield $(\bowtie) \cdot$ P. Rao-Balakrishna · H. Soran University Department of Medicine, Central

Manchester University Hospitals NHS Foundation

Trust, Manchester Academic Health Science Centre,

Manchester, UK

e-mail: jschofield@doctors.org.uk

R. A. Malik

Weill Cornell Medicine-Qatar, Doha, Qatar effect of medications commonly used in the management of diabetes on the lipid profile, the evidence for lifestyle and pharmaceutical interventions, and national and international recommendations for the management of dyslipidemia in patients with diabetes.

Keywords: Cardiovascular risk; Diabetes; Dyslipidemia; Lipoproteins; Low density lipoprotein cholesterol

\section{BACKGROUND}

Diabetes mellitus is associated with a considerably increased risk of premature atherosclerosis, particularly coronary heart disease (CHD) and peripheral arterial disease $[1,2]$. Although more recent analyses have suggested a less marked effect, most authorities consider diabetes to confer at least a twofold excess risk, independently from other conventional risk factors $[3,4]$. Even in people without diabetes, fasting blood glucose concentration and glycated hemoglobin (HbA1c) are associated with the risk of vascular disease $[3,5]$. 
Early studies of cardiovascular mortality in type 1 diabetes suggested that risk only significantly increases after the development of nephropathy, which coincides with a marked deterioration of the lipid profile and blood pressure [6]. In patients with type 1 diabetes and proteinuria a 37 -fold excess risk has been described, compared with a relative risk of 4.3 in patients without proteinuria [7]. Importantly this relative risk does not appear to be related to disease duration. More recent analyses have suggested that improved management of other risk factors can reduce the overall relative risk to 3.0 for women and 2.3 for men [8].

In type 2 diabetes an increased cardiovascular risk often exists for many years before the onset of biochemical hyperglycemia. During this period obesity and insulin resistance are often present, associated with hypertension and dyslipidemia, usually referred to as metabolic syndrome [9]. These risk factors may lead to the early development of CHD and may account for the increased incidence of diabetes in the period following a diagnosis of cardiovascular disease [10]. In keeping with this observation, about one in six patients with newly diagnosed type 2 diabetes enrolled in the United Kingdom Prospective Diabetes Study (UKPDS; Controlled-Trials.com identifier: ISRCTN75451837) had evidence of previous silent myocardial infarction [11].

However, neither the Diabetes Control and Complications Trial (DCCT; ClinicalTrials.gov identifier: NCT00360815) or the UKPDS (apart from 342 patients in the UKPDS metformin subgroup) showed a statistically significant reduction in $\mathrm{CHD}$ risk with more intensive glycemic control [12, 13]. Both the Action in Diabetes and Vascular Disease (ADVANCE; ClinicalTrials.gov identifier: NCT00145925) and Veterans Affairs Diabetes (VADT; ClinicalTrials.gov identifier: NCT00032487) trials also failed to show the desired beneficial effects on cardiovascular outcomes from intensive glycemic control [14, 15]. This apparent lack of effect was confirmed in the Outcome Reduction with Initial Glargine Intervention (ORIGIN; ClinicalTrials.gov identifier: NCT00069784) trial with insulin [16]. Reassuringly, prior intensive therapy was associated with long-term reductions in CHD during the observational follow-up studies of both the DCCT and UKPDS [17, 18], although the Action to Control Cardiovascular Risk in Diabetes (ACCORD; ClinicalTrials.gov identifier: NCT00000620) study group reported previously unrecognized harm from intensive glucose lowering in patients with type 2 diabetes with established cardiovascular disease or additional cardiovascular risk factors [19].

Dyslipidemia is a common feature of diabetes [20]. There is an association between atherosclerotic cardiovascular disease and serum cholesterol and triglyceride levels in both type 1 and type 2 diabetes [21, 22]. The risk of $\mathrm{CHD}$ is greater at any given level of serum cholesterol in patients with diabetes and its association with hypertriglyceridemia is stronger than in the general population [23]. Importantly, there is strong and convincing evidence that cholesterol lowering therapy significantly reduces CHD in patients both with and without diabetes [24-26]. There also appears to be no threshold below which a further reduction in low-density lipoprotein (LDL) cholesterol might be beneficial $[25,26]$.

Improved glycemic control generally has favorable effects on lipoprotein levels in diabetes, with a reduction in cholesterol and triglyceride levels through decreased circulating very-low-density lipoprotein (VLDL) and by increased catabolism of LDL through reduced glycation and upregulation of LDL receptors 
$[27,28]$. It is certainly possible that any cardiovascular benefit which might be derived from intensive glucose lowering is related to effects on lipoprotein metabolism rather than directly through altered glycemia [29].

This article is based on previously conducted studies and does not involve any new studies of human or animal subjects performed by any of the authors.

\section{DYSLIPIDEMIA AND ATHEROSCLEROSIS IN DIABETES}

The dyslipidemia of type 2 diabetes is characterized by high triglyceride levels and decreased high-density lipoprotein (HDL) cholesterol, changes observed many years before the onset of clinically relevant hyperglycemia $[9,30]$. Recent evidence suggests that low HDL cholesterol is an independent factor not only for cardiovascular disease but also for the development of diabetes itself [31]. These changes, and the presence of small dense LDL particles, probably contribute to accelerated atherosclerosis even before diabetes is formally diagnosed [9, 32]. In type 1 diabetes, hypertriglyceridemia may occur, but HDL cholesterol levels are often normal or even high unless glycemic control is poor or nephropathy is present [30]. In addition, patients with diabetes show qualitative and kinetic abnormalities for all lipoproteins [33].

A number of factors may contribute to the alterations in lipid metabolism observed in patients with diabetes, including insulin deficiency or resistance, adipocytokines, and hyperglycemia [33]. Many aspects of the pathophysiology and consequences of diabetes dyslipidemia remain unclear, but the mechanism by which hypertriglyceridemia arises is fairly well understood [34]. Insulin deficiency or resistance activates intracellular hormone-sensitive lipase which increases the release of non-esterified fatty acids (NEFA) from triglycerides stored in the more metabolically active centrally distributed adipose tissue [35]. High circulating levels of NEFA increase hepatic triglyceride production. Increased hepatic triglyceride synthesis is associated with increased secretion of apolipoprotein B (apoB) [36] (see Fig. 1). Furthermore, the normal inhibitory effect of insulin on hepatic apoB production and triglyceride secretion in VLDL is lost, and the VLDL secreted is larger and more triglyceride-rich [37-39]. The tendency to hypertriglyceridemia is further augmented by reduced VLDL catabolism [33]. Lipoprotein lipase located on vascular endothelium largely determines the rate of removal of triglycerides from the circulation. In contrast to intracellular hormone-sensitive lipase this lipoprotein lipase may be downregulated in states of insulin resistance or deficiency [33]. This reduction in lipoprotein lipase activity also contributes to postprandial lipemia [40].

It is essential to rectify the commonly held misconception that triglyceride concentration is a poor indicator of cardiovascular risk. There is a strong relationship between triglycerides and CHD in both type 1 and type 2 diabetes. Raised serum triglycerides herald the development of type 2 diabetes mellitus, particularly when associated with other features of metabolic syndrome or CHD, and once diabetes has developed they continue to predict CHD risk, often independently of other risk factors [21]. Triglycerides are positively correlated with cholesterol, obesity, glucose intolerance, cigarette smoking, and hyperuricemia, and are negatively correlated with HDL cholesterol. When these factors are 


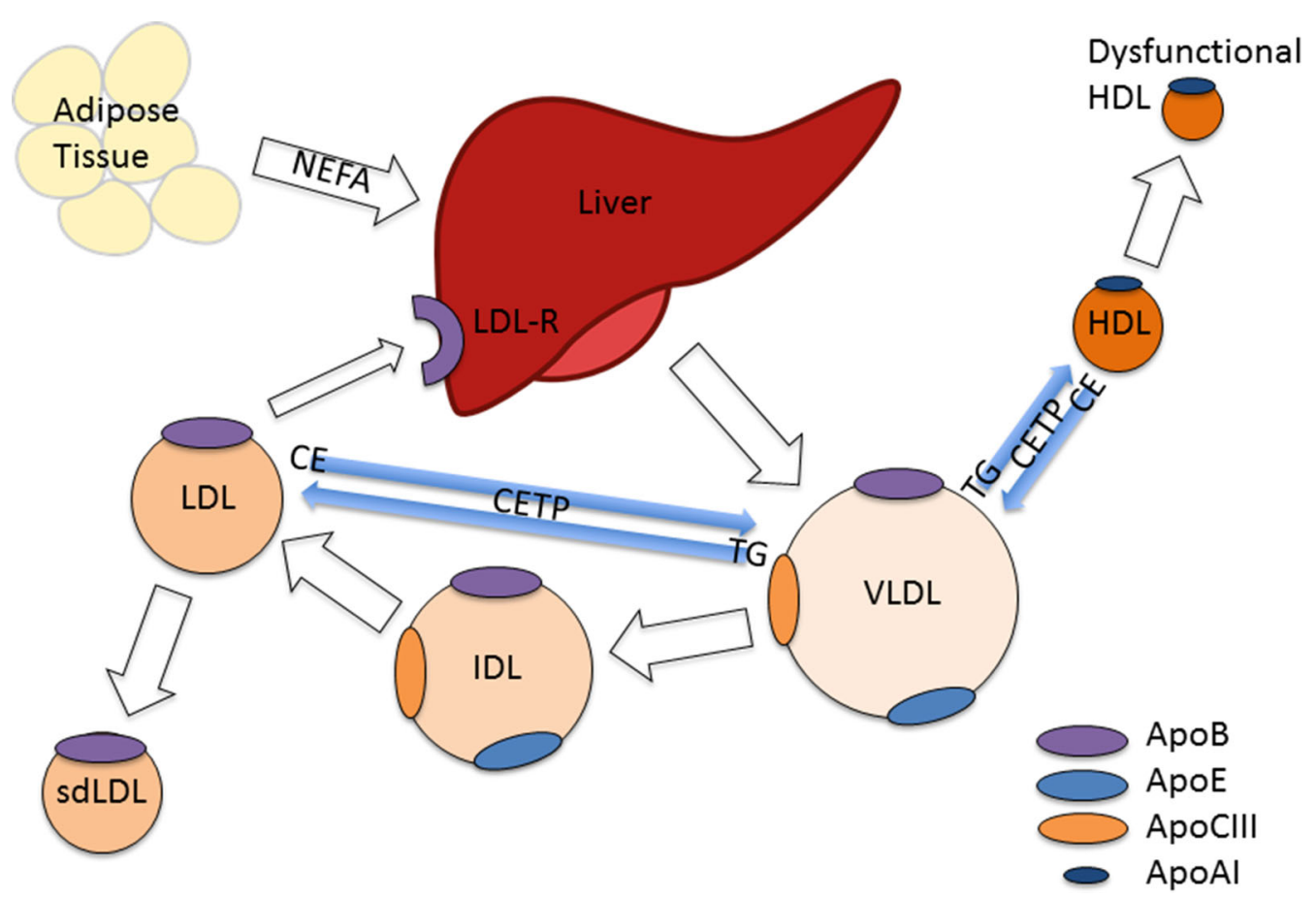

Fig. 1 Qualitative changes in lipoproteins in diabetes. $A p o A I$ apolipoprotein AI, $A p o B$ apolipoprotein B, ApoCIII apolipoprotein CIII, $A p o E$ apolipoprotein E, $C E$ cholesteryl esters, CETP cholesteryl ester transfer protein, $H D L$ high-density lipoprotein, IDL intermediate-density

included in multivariate analysis, the element of risk attributable to triglycerides themselves appears less significant, but the risk associated with hypertriglyceridemia is still substantial with fasting levels of $2.6-4.5 \mathrm{mmol} / \mathrm{L}$ associated with a twofold excess of CHD risk and levels of $4.5-9.0 \mathrm{mmol} / \mathrm{L}$ with up to a ninefold elevation [41, 42].

Triglyceride-rich lipoproteins (chylomicrons and VLDL) are not known to participate directly in atherogenesis, but they are central to the mechanism by which small dense LDL cholesterol is generated and HDL cholesterol levels are depressed in diabetes [1]. Cholesteryl ester is transferred from other lipoproteins into the enlarged circulating pool of triglyceride-rich lipoproteins by cholesteryl ester transfer protein, and the rate of transfer is increased in lipoprotein, $L D L$ low-density lipoprotein, $L D L-R$ low-density lipoprotein receptor, $N E F A$ non-esterified fatty acids, sdLDL small dense low-density lipoprotein, $T G$ triglycerides, $V L D L$ very-low-density lipoprotein

both type 1 and type 2 diabetes [43, 44]. There is transfer of triglyceride in the opposite direction such that cholesteryl ester-depleted HDL and LDL become triglyceride-rich. The subsequent removal of this triglyceride by hepatic lipase results in smaller, denser HDL and LDL particles.

Levels of small dense LDL are thus increased, and the apparently relatively undisturbed cholesterol and apoB levels observed in many patients with diabetes may thus hide a major atherogenic change [45-47]. Circulating LDL is not believed to participate directly in atherogenesis, but must first undergo structural modification to allow its apoB to act as a ligand for the scavenger receptors of monocyte macrophages in the arterial wall, triggering foam cell formation [48]. The 
proportion of glycated apoB is doubled even in reasonably well-controlled diabetes [28]. Glycated LDL may be more susceptible to oxidation or itself represent an atherogenic modification [49, 50]. Glycation of LDL also decreases its LDL receptor-mediated catabolism [51].

In patients with type 1 diabetes with good glycemic control, insulin upregulates lipoprotein lipase, increasing the production of small HDL particles [52, 53], frequently to higher than normal HDL cholesterol levels [54]. HDL cholesterol in diabetes has thus not arisen physiologically; HDL dysfunction is suggested by the observation that high HDL cholesterol levels do not always protect against CHD [55, 56]. HDL may be dysfunctional in its capacity to protect LDL against atherogenic modification. Reductions in the antioxidative and anti-inflammatory effects of HDL have been reported in patients with diabetes, alongside an impaired ability of HDL to counteract the inhibition of endothelium-dependent vasorelaxation by oxidized LDL $[34,57]$. The role of HDL in protecting pancreatic beta cells against apoptosis is an important emerging area of research [58]. Glycation has recently been shown to reduce the sphingosine-1-phosphate content of HDL, reducing its ability to activate protective intracellular survival pathways during oxidative stress [59].

With the development of nephropathy, increased catabolism of smaller HDL particles likely combines with increased cholesteryl ester activity to lower HDL cholesterol levels $[6,60]$. Glycation of HDL further enhances its catabolism [61]. Diabetes thus leads to impaired reverse cholesterol transport through both reduced HDL concentrations and HDL dysfunction [36]. Low HDL cholesterol appears to be of greater importance in patients at high cardiometabolic risk and is amongst the factors that currently favor a decision to further reduce LDL cholesterol levels [20].

\section{CLINICAL INVESTIGATIONS}

The apparently normal serum cholesterol concentrations observed in both type 1 and type 2 diabetes led to the widespread erroneous belief that glycemia alone might explain the observed high CHD rates. However, the relatively normal cholesterol levels hide an atherogenic lipid profile, with increased intermediate-density lipoprotein and small dense LDL, and dysfunctional HDL [49-51].

Each LDL particle, regardless of its density or cholesterol content, contains only a single tightly bound molecule of apoB. The often "normal" level of LDL cholesterol seen in many patients with diabetes actually disguises an increased particle number (higher apoB) and that clearance of small dense particles is slower [20]. Thus, measurement of the serum concentration of apoB provides a more discriminating index of atherogenic risk or therapeutic response than LDL cholesterol [62]. While intensive therapy in the DCCT did not significantly affect LDL and HDL cholesterol levels, it was associated with decreased apoB (and lipoprotein(a)) and with favorable alterations in lipoprotein subclasses that are not revealed by the standard lipid profile, but have implications for the evolution of both microvascular and macrovascular complications [63].

The use of LDL cholesterol in diabetes also underestimates the atherogenic contribution of triglyceride-rich particles so non-HDL cholesterol is a better measure of atherogenicity in diabetes [64]. The introduction of non-HDL cholesterol appears 
to have obviated the need to introduce apoB measurements more widely in patient management.

\section{DIET AND WEIGHT MANAGEMENT}

Lifestyle modifications are the first-line intervention in the management of diabetes dyslipidemia, and include weight loss, dietary modification, and aerobic exercise [36]. Obesity increases insulin resistance and is associated with increased triglycerides and LDL cholesterol and decreased HDL cholesterol [1]. Weight loss is known to be associated with improvements in lipids and other cardiovascular risk factors including the incidence of type 2 diabetes [65, 66] and should therefore be encouraged in overweight patients with diabetes. To achieve sustained weight loss, caloric restriction remains the key and even modest degrees of weight loss are associated with an improvement in glycemic control, HbA1c, and lipid profile [67].

Increased physical activity may provide some small adjunct to the effect of dietary restriction, but is unlikely to be successful on its own. Reduced fat intake, particularly of saturated fat, should also be encouraged [68]. The American Diabetes Association (ADA) recommends a diet low in trans fat, saturated fat, and cholesterol [69]. In patients without a marked increase in serum triglycerides but who are not obese, some substitution of saturated fat can be made with unrefined carbohydrate foods and some with oleic, linoleic, or omega-3 fish oils [70].

Dietary interventions, while considered first-line treatment for all patients with diabetes, have not been successful in demonstrating a mortality benefit, even with prolonged follow-up [71].
The gastrointestinal lipase inhibitor orlistat causes fat malabsorption and should be taken close to meals. The patient must adhere to a low fat diet or they will experience steatorrhoea. There is often early benefit, but then weight loss levels out, likely as the patient learns to omit it if they plan to consume a fatty meal. Nonetheless any weight loss achieved can improve cardiovascular risk factors [72]. Orlistat has beneficial effects on serum total and LDL cholesterol levels which are greater than might be explained by weight loss alone [73].

Surgical management of obesity is much more effective than medical treatment [65]. Weight loss after bariatric surgery is also associated with beneficial glycemic effects in diabetes, including achievement of near normal glycemia without medication or reduced medications [74].

\section{EFFECTS OF HYPOGLYCEMIC AGENTS ON LIPOPROTEINS}

Diabetes dyslipidemia can be partly corrected by insulin treatment and improved blood glucose control [75]. Insulin therapy increases HDL cholesterol and reduces circulating triglyceride levels, particularly in patients with poor glycemic control [76]. Metformin decreases serum triglycerides and improves insulin resistance but is often overlooked as a lipid-lowering agent and is generally considered only as a hypoglycemic agent in the management of diabetes [77]. Other drugs used in the management of diabetes may also have unintended positive and negative effects on lipoproteins (see Table 1). Of particular interest is the small increase in LDL cholesterol observed following treatment with sodium-glucose cotransporter 2

(SGLT2) 
Table 1 Effects of hypoglycemic agents on lipoproteins

\begin{tabular}{llllll}
\hline Drug & Total cholesterol & LDL cholesterol & HDL cholesterol & Triglycerides & References \\
\hline Metformin & $\downarrow \leftrightarrow$ & $\downarrow$ & $\leftrightarrow \uparrow$ & $\downarrow \leftrightarrow$ & {$[114]$} \\
Gliclazide & $\downarrow$ & $\leftrightarrow$ & $\leftrightarrow$ & $\downarrow$ & {$[115,116]$} \\
Glimepiride & $\leftrightarrow$ & $\leftrightarrow$ & $\leftrightarrow \uparrow$ & $\downarrow$ & {$[115,117]$} \\
Pioglitazone & $\uparrow$ & $\leftrightarrow$ & $\uparrow$ & $\leftrightarrow$ & {$[118,119]$} \\
Sitagliptin & $\leftrightarrow$ & $\leftrightarrow$ & $\leftrightarrow$ & $\leftrightarrow$ & {$[120,121]$} \\
Saxagliptin & $\leftrightarrow$ & $\leftrightarrow$ & $\leftrightarrow$ & {$[116,122]$} \\
Vildagliptin & $\leftrightarrow$ & $\leftrightarrow$ & $\leftrightarrow$ & {$[123]$} \\
Linagliptin & $\leftrightarrow$ & $\leftrightarrow$ & $\downarrow$ & {$[124]$} \\
Dapagliflozin & $\leftrightarrow \uparrow$ & $\leftrightarrow$ & $\uparrow$ & {$[125,126]$} \\
Canagliflozin & $\uparrow$ & $\leftrightarrow \uparrow$ & $\leftrightarrow$ & $\leftrightarrow$ & {$[121,127]$} \\
Empagliflozin & $\leftrightarrow \uparrow$ & $\leftrightarrow$ & $\leftrightarrow \uparrow$ & $\downarrow$ & {$[78,128]$} \\
Exenatide & $\downarrow \leftrightarrow$ & $\leftrightarrow \uparrow$ & $\leftrightarrow$ & $\downarrow$ & {$[119,129]$} \\
Liraglutide & $\leftrightarrow$ & $\leftrightarrow$ & $\leftrightarrow$ & {$[130,131]$} \\
\hline
\end{tabular}

$\uparrow$ Increased, $\leftrightarrow$ no change, $\downarrow$ decreased, $H D L$ high-density lipoprotein, $L D L$ low-density lipoprotein

inhibitors, suggesting that the recently reported significant improvement in cardiovascular outcomes with empagliflozin is unrelated to effects on dyslipidemia [78].

\section{LIPID-LOWERING DRUGS}

The discovery of statins was a key advance in cardiovascular medicine. Statins inhibit 3-hydroxy-3-methylglutaryl-coenzyme A reductase, the rate-limiting enzyme in cholesterol biosynthesis. There is a wealth of clinical trial evidence that lowering serum cholesterol with statins decreases the risk of CHD [24, 79]. These trials have demonstrated that statins decrease the risk of both CHD and stroke in people with and without pre-existing cardiovascular disease [24, 80]. It would appear from such trials that the relative risk reduction achieved with statin treatment is similar in patients with diabetes to that in other people. However, the number needed to treat to prevent one event (NNT) will be lower in patients with diabetes compared to those without diabetes but apparently similar lipid profiles [81].

The case for secondary prevention with statin therapy in diabetes is accepted, but whether all patients with diabetes should be considered for statin treatment has been more contentious. In the Heart Protection Study (Controlled-Trials.com identifier: ISRCTN48489393) the 2912 patients with diabetes without pre-existing vascular disease randomized to receive simvastatin showed a significant reduction in cardiovascular end-points compared to those allocated to placebo [82]. Similarly, in the Collaborative Atorvastatin Diabetes Study (CARDS; ClinicalTrials.gov identifier: NCT00327418), where the mean pretreatment LDL cholesterol was $3.0 \mathrm{mmol} / \mathrm{L} \quad(<2.5 \mathrm{mmol} / \mathrm{L}$ in $25 \%$ of patients), the effect of active intervention with 
atorvastatin was so favorable that the study was stopped early [24]. In both studies there did not appear to be any threshold below which statin therapy ceased to be beneficial. A meta-analysis of 18,686 people with diabetes from 14 randomized trials (1466 with type 1 and 17,220 with type 2) demonstrated a 9\% reduction in all-cause mortality for every $1 \mathrm{mmol} / \mathrm{L}$ reduction in LDL cholesterol [26]. The effects of statin therapy were similar irrespective of baseline characteristics and prior history of vascular disease. Although the majority of participants in these trials had type 2 diabetes, the reduction in major vascular events was also statistically significant in people with type 1 diabetes.

The risk factor reduction brought about by statins occurs in a dose-dependent fashion, with higher dose statins associated with a greater lowering of cardiovascular events [83]. It should also be noted that in diabetes, in contrast to patients without diabetes, statins do not stop the progression of carotid intima media thickness or intravascular ultrasound-measured atheroma volume at typical doses, implying that high doses may be necessary to prevent atheroma progression [84]. One in seven patients with diabetes treated with statins still goes on to suffer a cardiovascular event over 5 years [26].

Clinical trial evidence therefore provides unequivocal evidence to support prescribing statins for both primary and secondary prevention in diabetes, but the populations studied may not be representative of younger patients or those with advanced renal disease. This requires further exploration and thus the exercise of clinical judgment in prescribing.

Interestingly, statin treatment is associated with a slight increase in the incidence of type 2 diabetes. A meta-analysis showed 4 years of statin treatment in 255 patients would lead to one extra case of type 2 diabetes [85]. However, this risk is low both in absolute terms and when compared with the expected cardiovascular benefit from reducing LDL cholesterol. In the same period 5.4 vascular events would be avoided in these 255 patients [85]. Clinical practice in patients with existing cardiovascular disease or moderate or high cardiovascular risk should not change.

Ezetimibe blocks the absorption of dietary cholesterol and the reabsorption of cholesterol entering the small intestine in bile, the latter accounting for most of its LDL cholesterol lowering. Ezetimibe is concentrated in the cells of the intestinal brush border, where it inhibits cholesterol absorption by a process which involves binding to Niemann-Pick C1-Like 1 [86]. It remains a second-line option for LDL cholesterol lowering in diabetes and has its greatest clinical utility as an adjunct to statin therapy.

The bile acid sequestrant colesevelam has been shown to reduce $\mathrm{HbA1c}$ in addition to reductions in total cholesterol, LDL, and non-HDL cholesterol levels [87]. Cholestyramine may be more effective in lowering LDL cholesterol, but both agents may increase triglycerides, and neither is particularly well tolerated [88].

Many novel therapies are in development to reduce LDL cholesterol, but none has been studied specifically in patients with diabetes [89]. In particular, proprotein convertase subtilisin/kexin 9 (PCSK9) inhibitors have emerged as medications showing significant reductions in LDL, with recent data suggesting similar effects on lipoproteins in patients with type 2 diabetes to those seen in patients without diabetes [90]. An additional potentially beneficial effect on postprandial 
hypertriglyceridemia is suggested by novel data on PCSK9 regulation of intestinal lipoprotein assembly and secretion [91]. Ongoing cardiovascular outcome trials will inform the use of PCSK9 inhibitors in diabetes.

The ACCORD study showed an increased number of cardiovascular events in patients with diabetes and persistently low HDL cholesterol and high triglyceride levels, despite a mean LDL cholesterol below $2.1 \mathrm{mmol} / \mathrm{L}$ [92]. Fibrates act as peroxisome proliferator-activated receptor (PPAR)- $\alpha$ agonists to reduce triglycerides and modestly increase HDL cholesterol but also affect multiple pathways linked to the retinoid-X receptor [93]. To date no decrease in cardiovascular outcomes has been convincingly demonstrated in clinical trials [94]. In the Fenofibrate Intervention and Event Lowering in Diabetes (FIELD; Controlled-Trials.com identifier: ISRCTN64783481) study 9795 people with type 2 diabetes were randomized to receive micronized fenofibrate or placebo [95]. By the end of the trial statin treatment became a major confounding factor, but the primary end-point (fatal CHD and non-fatal myocardial infarction) decreased by $11 \%$ on fenofibrate compared to placebo. Although pretreatment serum triglyceride levels appeared to have no influence on the relative decrease in cardiovascular events, the overall effect was not significant, and the FIELD study did not establish a firm place for fibrate drugs in the management of diabetes dyslipidemia. More recently the ACCORD-LIPID trial reported no cardiovascular benefit from the addition of fenofibrate to simvastatin in patients with type 2 diabetes [92]. However, there did appear to be a beneficial effect on CHD outcomes in patients with triglycerides above $2.4 \mathrm{mmol} / \mathrm{L}$ and HDL cholesterol below $0.79 \mathrm{mmol} / \mathrm{L}$ [92].
There may therefore be a role for fibrates as adjunctive therapy in patients with diabetes and persistently elevated triglycerides. However, fibrates, particularly fenofibrate, may cause paradoxical reductions in HDL cholesterol levels and it is important that clinicians are aware of this phenomenon [96].

Most hypertriglyceridemia in diabetes is mild to moderate and statins remain the drug of first choice even in patients with mixed dyslipidemias, but in patients with genetic susceptibility severe hypertriglyceridemia may develop, with attendant risk of pancreatitis [97]. When triglycerides are above $11 \mathrm{mmol} / \mathrm{L}$ a fibrate should be considered first to reduce triglycerides and the risk of pancreatitis.

Purified omega-3 fatty acids can lower triglycerides as much as fibrates, but they have little effect on HDL or LDL cholesterol [98]. Omacor $^{\circledR}$ (Abbott Healthcare, Abbott Park, IL, USA) contains 90\% omega-3 fatty acid ethyl esters (mostly eicosopentaenoate or docosahexaenoate) and in combination with a statin can decrease triglycerides by a further $30 \%$, most probably by inhibition of hepatic triglyceride synthesis [99]. Despite evidence that omega-3 fatty acids stabilize atheromatous plaques and reports of beneficial hypotensive and antithrombotic effects, a recent trial of omega-3 fatty acids in patients with metabolic syndrome or type 2 diabetes disappointingly found no effect on CHD risk [100, 101].

Another future therapeutic option may be the dual PPAR- $\alpha / \gamma$ agonist saroglitazar, which was approved in India in 2013 and has been shown to significantly reduce plasma triglyceride, total cholesterol, non-HDL cholesterol, and VLDL cholesterol, and HbA1c and fasting glucose levels [102]. 


\section{NATIONAL AND INTERNATIONAL RECOMMENDATIONS FOR THE MANAGEMENT OF HYPERLIPIDEMIA}

The role of diabetes in risk assessment processes is more controversial than the simple statement often applied in guidelines that diabetes is a cardiovascular disease-risk equivalent. Risk in type 1 diabetes is strongly related to glycemic control, nephropathy, and hypertension and can be significantly increased compared with normoglycemic subjects [103]. Risk in type 2 diabetes is still widely considered to be increased two- to fourfold [3, 104]. While features such as the presence of nephropathy or retinopathy identify higher risk groups, the use of other biomarkers of risk and likely need for enhanced treatment are often not appreciated. The presence of microalbuminuria for example is a risk factor for CHD even at low levels and its severity is also predictive of future events [105].

Most clinical guidelines recommend tight control of dyslipidemia, especially in high risk patients [106, 107]. Importantly, lipid targets are easier to achieve than blood pressure or glycemia targets and target LDL cholesterol levels as low as $1.8 \mathrm{mmol} / \mathrm{L}$ are increasingly recommended in patients with established CHD [108, 109].

A recent position statement from the ADA recommends a screening lipid profile at the time of diagnosis, at age 40 years, and periodically thereafter [110]. Treatment recommendations beyond lifestyle modification and optimization of glycemic control are for the use of high-intensity statin therapy (e.g., atorvastatin $40-80 \mathrm{mg}$ or rosuvastatin $20-40 \mathrm{mg}$ ) in patients of all ages with overt CHD, and those aged 40-75 years with additional risk factors, and moderate intensity statin therapy (e.g., atorvastatin $10-20 \mathrm{mg}$ or simvastatin $20-40 \mathrm{mg}$ ) for patients aged over 40 years without additional risk factors. Clinical judgment should guide the use of moderate or high-intensity statin therapy in patients younger than 40 years or older than 75 years with additional risk factors [110].

The most recent American Heart Association/American College of Cardiology guidelines for cholesterol management appear less interventional, recommending statin treatment only for patients with diabetes with clinical atherosclerotic cardiovascular disease or if aged 40-75 years [111]. There is also a modest recommendation for additional treatment in persons with statin intolerance or an inadequate response, with an emphasis on clinical judgment. The European Society of Cardiology suggests that ezetimibe be added after intensification of statin therapy in diabetes [112].

The National Institute for Health and Care Excellence also recently updated its guidance and now advises clinicians to offer statin treatment for primary prevention to adults with type 1 diabetes who are over 40 years, have had diabetes for more than 10 years, or have established nephropathy or other cardiovascular risk factors [113]. These guidelines also recommend statin therapy for primary prevention in type 2 diabetes if the 10 -year risk of developing cardiovascular disease is estimated to be greater than $10 \%$ using the QRISK2 assessment tool [113].

In conclusion, statin treatment should effectively be considered for all people with diabetes aged over 40 years or younger if additional cardiovascular risk factors are present, a position recently supported by the Joint British Societies [106]. 


\section{ACKNOWLEDGMENTS}

This work was facilitated by the Greater Manchester Local Clinical Research Network and the National Institute for Health Research/ Wellcome Trust Clinical Research Facility in Manchester. No funding or sponsorship was received for publication of this article. All named authors meet the International Committee of Medical Journal Editors (ICMJE) criteria for authorship for this manuscript, take responsibility for the work as a whole, and have given final approval to the version to be published.

Disclosures. Jonathan D. Schofield, Yifen Liu, and Prasanna Rao-Balakrishna have no conflicts of interest to declare. Rayaz A. Malik has received research grants from Diabetes UK, National Health and Medical Research Council (NHMRC) of Australia, JDRF International, National Institute for Health Research (NIHR), Sanofi, Tranzyme Pharma, and MSD. Handrean Soran has received research grants from Synageva, Pfizer, Amgen, and MSD.

Compliance with Ethics Guidelines. This article is based on previously conducted studies and does not involve any new studies of human or animal subjects performed by any of the authors.

Open Access. This article is distributed under the terms of the Creative Commons AttributionNonCommercial 4.0 International License (http://creativecommons.org/licenses/by-nc/4. $0 /$ ), which permits any noncommercial use, distribution, and reproduction in any medium, provided you give appropriate credit to the original author(s) and the source, provide a link to the Creative Commons license, and indicate if changes were made.

\section{REFERENCES}

1. Durrington PN. Hyperlipidaemia: diagnosis and management. London: Hodder Arnold; 2007.

2. Laing SP, Swerdlow AJ, Slater SD, et al. Mortality from heart disease in a cohort of 23,000 patients with insulin-treated diabetes. Diabetologia. 2003;46:760-5.

3. Emerging Risk Factors Collaboration, Sarwar N, Gao P, et al. Diabetes mellitus, fasting blood glucose concentration, and risk of vascular disease: a collaborative meta-analysis of 102 prospective studies. Lancet. 2010;375:2215-22.

4. Emerging Risk Factors Collaboration, Seshasai SR, Kaptoge S, et al. Diabetes mellitus, fasting glucose, and risk of cause-specific death. N Engl J Med. 2011;364:829-41.

5. Selvin E, Steffes MW, Zhu $\mathrm{H}$, et al. Glycated hemoglobin, diabetes, and cardiovascular risk in nondiabetic adults. N Engl J Med. 2010;362:800-11.

6. Winocour PH, Durrington PN, Ishola M, Anderson DC, Cohen H. Influence of proteinuria on vascular disease, blood pressure, and lipoproteins in insulin dependent diabetes mellitus. Br Med J (Clin Res Ed). 1987;294:1648-51.

7. Borch-Johnsen K, Kreiner S. Proteinuria: value as predictor of cardiovascular mortality in insulin dependent diabetes mellitus. Br Med J (Clin Res Ed). 1987;294:1651-4.

8. Livingstone SJ, Looker HC, Hothersall EJ, et al. Risk of cardiovascular disease and total mortality in adults with type 1 diabetes: Scottish registry linkage study. PLoS Med. 2012;9:e1001321.

9. Haffner SM, Stern MP, Hazuda HP, Mitchell BD, Patterson JK. Cardiovascular risk factors in confirmed prediabetic individuals. Does the clock for coronary heart disease start ticking before the onset of clinical diabetes? JAMA. 1990;263:2893-8.

10. Farrer M, Fulcher G, Albers CJ, et al. Patients undergoing coronary artery bypass graft surgery are at high risk of impaired glucose tolerance and diabetes mellitus during the first postoperative year. Metabolism. 1995;44:1016-27.

11. Davis TM, Coleman RL, Holman RR, Group U. Prognostic significance of silent myocardial infarction in newly diagnosed type 2 diabetes mellitus: United Kingdom Prospective Diabetes Study (UKPDS) 79. Circulation. 2013;127:980-7. 
12. Diabetes Control and Complications Trial (DCCT) Research Group. Effect of intensive diabetes management on macrovascular events and risk factors in the Diabetes Control and Complications Trial. Am J Cardiol. 1995;75:894-903.

13. UK Prospective Diabetes Study (UKPDS) Group. Intensive blood-glucose control with sulphonylureas or insulin compared with conventional treatment and risk of complications in patients with type 2 diabetes (UKPDS 33). Lancet. 1998;352:837-853.

14. Duckworth W, Abraira C, Moritz T, et al. Glucose control and vascular complications in veterans with type 2 diabetes. $\mathrm{N}$ Engl J Med. 2009;360:129-39.

15. ADVANCE Collaborative Group, Patel A, MacMahon $S$, et al. Intensive blood glucose control and vascular outcomes in patients with type 2 diabetes. N Engl J Med. 2008;358:2560-72.

16. Investigators OT, Gerstein HC, Bosch J, et al. Basal insulin and cardiovascular and other outcomes in dysglycemia. N Engl J Med. 2012;367:319-28.

17. Lachin JM, Orchard TJ, Nathan DM, DCCT/EDIC Research Group. Update on cardiovascular outcomes at 30 years of the diabetes control and complications trial/epidemiology of diabetes interventions and complications study. Diabetes Care. 2014;37:39-43.

18. Holman RR, Paul SK, Bethel MA, Matthews DR, Neil HA. 10-year follow-up of intensive glucose control in type 2 diabetes. $\mathrm{N}$ Engl J Med. 2008;359:1577-89.

19. Action to Control Cardiovascular Risk in Diabetes Study Group, Gerstein HC, Miller ME, et al. Effects of intensive glucose lowering in type 2 diabetes. N Engl J Med. 2008;358:2545-59.

20. Chapman MJ, Ginsberg HN, Amarenco P, et al. Triglyceride-rich lipoproteins and high-density lipoprotein cholesterol in patients at high risk of cardiovascular disease: evidence and guidance for management. Eur Heart J. 2011;32:1345-61.

21. West KM, Ahuja MM, Bennett PH, et al. The role of circulating glucose and triglyceride concentrations and their interactions with other "risk factors" as determinants of arterial disease in nine diabetic population samples from the WHO multinational study. Diabetes Care. 1983;6:361-9.

22. Howard BV, Robbins DC, Sievers ML, et al. LDL cholesterol as a strong predictor of coronary heart disease in diabetic individuals with insulin resistance and low LDL: the Strong Heart Study. Arterioscler Thromb Vasc Biol. 2000;20:830-5.
23. Stamler J, Vaccaro O, Neaton JD, Wentworth D. Diabetes, other risk factors, and 12-yr cardiovascular mortality for men screened in the Multiple Risk Factor Intervention Trial. Diabetes Care. 1993;16:434-44.

24. Colhoun HM, Betteridge DJ, Durrington PN, et al. Primary prevention of cardiovascular disease with atorvastatin in type 2 diabetes in the collaborative atorvastatin diabetes study (CARDS): multicentre randomised placebo-controlled trial. Lancet. 2004;364:685-96.

25. Baigent C, Keech A, Kearney PM, et al. Efficacy and safety of cholesterol-lowering treatment: prospective meta-analysis of data from 90,056 participants in 14 randomised trials of statins. Lancet. 2005;366:1267-78.

26. Cholesterol Treatment Trialists Collaborators, Kearney PM, et al. Efficacy of cholesterol-lowering therapy in 18,686 people with diabetes in 14 randomised trials of statins: a meta-analysis. Lancet. 2008;371:117-25.

27. Pietri AO, Dunn FL, Grundy SM, Raskin P. The effect of continuous subcutaneous insulin infusion on very-low-density lipoprotein triglyceride metabolism in type I diabetes mellitus. Diabetes. 1983;32:75-81.

28. Tames FJ, Mackness MI, Arrol S, Laing I, Durrington PN. Non-enzymatic glycation of apolipoprotein B in the sera of diabetic and non-diabetic subjects. Atherosclerosis. 1992;93:237-44.

29. Ray KK, Seshasai SR, Wijesuriya S, et al. Effect of intensive control of glucose on cardiovascular outcomes and death in patients with diabetes mellitus: a meta-analysis of randomised controlled trials. Lancet. 2009;373:1765-72.

30. Dean JD, Durrington PN. Treatment of dyslipoproteinaemia in diabetes mellitus. Diabet Med. 1996;13:297-312.

31. Abbasi A, Corpeleijn E, Gansevoort RT, et al. Role of HDL cholesterol and estimates of HDL particle composition in future development of type 2 diabetes in the general population: the PREVEND study. J Clin Endocrinol Metab. 2013;98:E1352-9.

32. Steinberg D, Parthasarathy S, Carew TE, Khoo JC, Witztum JL. Beyond cholesterol. Modifications of low-density lipoprotein that increase its atherogenicity. N Engl J Med. 1989;320:915-24.

33. Taskinen MR. Diabetic dyslipidaemia: from basic research to clinical practice. Diabetologia. 2003;46:733-49. 
34. Verges B. Pathophysiology of diabetic dyslipidaemia: where are we? Diabetologia. 2015;58:886-99.

35. Nikkila EA, Kekki M. Plasma triglyceride transport kinetics in diabetes mellitus. Metabolism. 1973;22:1-22.

36. Warraich HJ, Wong ND, Rana JS. Role for combination therapy in diabetic dyslipidemia. Curr Cardiol Rep. 2015;17:32.

37. McEneny J, O'Kane MJ, Moles KW, et al. Very low density lipoprotein subfractions in type II diabetes mellitus: alterations in composition and susceptibility to oxidation. Diabetologia. 2000;43:485-93.

38. Malmstrom R, Packard CJ, Caslake $M$, et al. Defective regulation of triglyceride metabolism by insulin in the liver in NIDDM. Diabetologia. 1997;40:454-62.

39. Cummings $\mathrm{MH}$, Watts GF, Umpleby AM, et al. Acute hyperinsulinemia decreases the hepatic secretion of very-low-density lipoprotein apolipoprotein B-100 in NIDDM. Diabetes. 1995;44:1059-65.

40. Chen YD, Swami S, Skowronski R, Coulston A, Reaven GM. Differences in postprandial lipemia between patients with normal glucose tolerance and noninsulin-dependent diabetes mellitus. J Clin Endocrinol Metab. 1993;76:172-7.

41. Assmann G, Schulte $H$, von Eckardstein A. Hypertriglyceridemia and elevated lipoprotein(a) are risk factors for major coronary events in middle-aged men. Am J Cardiol. 1996;77:1179-84.

42. Hulley SB, Rosenman RH, Bawol RD, Brand RJ. Epidemiology as a guide to clinical decisions. The association between triglyceride and coronary heart disease. N Engl J Med. 1980;302:1383-9.

43. Bagdade JD, Ritter MC, Subbaiah PV. Accelerated cholesteryl ester transfer in patients with insulin-dependent diabetes mellitus. Eur J Clin Invest. 1991;21:161-7.

44. Bhatnagar D, Durrington PN, Kumar S, Mackness MI, Boulton AJ. Plasma lipoprotein composition and cholesteryl ester transfer from high density lipoproteins to very low density and low density lipoproteins in patients with non-insulin-dependent diabetes mellitus. Diabet Med. 1996;13:139-44.

45. Krauss RM. Lipids and lipoproteins in patients with type 2 diabetes. Diabetes Care. 2004;27:1496-504
46. Sibley SD, Hokanson JE, Steffes MW, et al. Increased small dense LDL and intermediate-density lipoprotein with albuminuria in type 1 diabetes. Diabetes Care. 1999;22:1165-70.

47. Schonfeld G, Birge C, Miller JP, Kessler G, Santiago J. Apolipoprotein B levels and altered lipoprotein composition in diabetes. Diabetes. 1974;23:827-34.

48. Witztum JL, Steinberg D. Role of oxidized low density lipoprotein in atherogenesis. J Clin Invest. 1991;88:1785-92.

49. Younis N, Sharma R, Soran H, et al. Glycation as an atherogenic modification of LDL. Curr Opin Lipidol. 2008;19:378-84.

50. Jenkins AJ, Best JD, Klein RL, Lyons TJ. Lipoproteins, glycoxidation and diabetic angiopathy. Diabetes Metab Res Rev. 2004;20:349-68.

51. Witztum JL, Mahoney EM, Branks MJ, et al. Nonenzymatic glucosylation of low-density lipoprotein alters its biologic activity. Diabetes. 1982;31:283-91.

52. Taskinen MR. Lipoprotein lipase in diabetes. Diabetes Metab Rev. 1987;3:551-70.

53. Durrington PN. Serum high density lipoprotein cholesterol subfractions in type I (insulin-dependent) diabetes mellitus. Clin Chim Acta. 1982;120:21-8.

54. Durrington PN. Serum high density lipoprotein cholesterol in diabetes mellitus: an analysis of factors which influence its concentration. Clin Chim Acta. 1980;104:11-23.

55. Smith JD. Dysfunctional HDL as a diagnostic and therapeutic target. Arterioscler Thromb Vasc Biol. 2010;30:151-5.

56. Schofield JD, France M, Ammori B, Liu YF, Soran H. High-density lipoprotein cholesterol raising: does it matter? Curr Opin Cardiol. 2013;28:464-74.

57. Morgantini C, Natali A, Boldrini B, et al. Anti-inflammatory and antioxidant properties of HDLs are impaired in type 2 diabetes. Diabetes. 2011;60:2617-23.

58. von Eckardstein A, Widmann C. High-density lipoprotein, beta cells, and diabetes. Cardiovasc Res. 2014;103:384-94.

59. Brinck JW, Thomas A, Lauer E, et al. Diabetes mellitus is associated with reduced high-density lipoprotein sphingosine-1-phosphate content and 
impaired high-density lipoprotein cardiac cell protection. Arterioscler Thromb Vasc Biol. 2016. doi:10.1161/ATVBAHA.115.307049.

60. Short CD, Durrington PN, Mallick NP, et al. Serum and urinary high density lipoproteins in glomerular disease with proteinuria. Kidney Int. 1986;29:1224-8.

61. Witztum JL, Fisher M, Pietro T, Steinbrecher UP, Elam RL. Nonenzymatic glucosylation of high-density lipoprotein accelerates its catabolism in guinea pigs. Diabetes. 1982;31:1029-32.

62. Soran H, France MW, Kwok S, et al. Apolipoprotein B100 is a better treatment target than calculated LDL and non-HDL cholesterol in statin-treated patients. Ann Clin Biochem. 2011;48:566-71.

63. Zhang Y, Jenkins AJ, Basu A, et al. Associations between intensive diabetes therapy and NMR-determined lipoprotein subclass profiles in type 1 diabetes. J Lipid Res. 2016;57:310-7.

64. Emerging Risk Factors Collaboration, Di Angelantonio E, Sarwar N, et al. Major lipids, apolipoproteins, and risk of vascular disease. JAMA. 2009;302:1993-2000.

65. Sjostrom L, Lindroos AK, Peltonen $\mathrm{M}$, et al. Lifestyle, diabetes, and cardiovascular risk factors 10 years after bariatric surgery. N Engl J Med. 2004;351:2683-93.

66. Wood PD, Stefanick ML, Dreon DM, et al. Changes in plasma lipids and lipoproteins in overweight men during weight loss through dieting as compared with exercise. N Engl J Med. 1988;319:1173-9.

67. Rock CL, Flatt SW, Pakiz B, et al. Weight loss, glycemic control, and cardiovascular disease risk factors in response to differential diet composition in a weight loss program in type 2 diabetes: a randomized controlled trial. Diabetes Care. 2014;37:1573-80.

68. Grundy SM. Dietary therapy of hyperlipidaemia. Baillieres Clin Endocrinol Metab. 1987;1:667-98.

69. American Diabetes Association. Standards of medical care in diabetes-2014. Diabetes Care. 2014;37(Suppl 1):S14-80.

70. Haffner SM, American Diabetes Association. Dyslipidemia management in adults with diabetes. Diabetes Care. 2004;27(Suppl 1):S68-71.

71. Look ARG, Wing RR, Bolin P, et al. Cardiovascular effects of intensive lifestyle intervention in type 2 diabetes. N Engl J Med. 2013;369:145-54.
72. Torgerson JS, Hauptman J, Boldrin MN, Sjostrom L. XENical in the prevention of diabetes in obese subjects (XENDOS) study: a randomized study of orlistat as an adjunct to lifestyle changes for the prevention of type 2 diabetes in obese patients. Diabetes Care. 2004;27:155-61.

73. Davidson MH, Hauptman J, DiGirolamo M, et al. Weight control and risk factor reduction in obese subjects treated for 2 years with orlistat: a randomized controlled trial. JAMA. 1999;281:235-42.

74. Sjostrom L. Surgical intervention as a strategy for treatment of obesity. Endocrine. 2000;13:213-30.

75. Maahs DM, Ogden LG, Dabelea D, et al. Association of glycaemia with lipids in adults with type 1 diabetes: modification by dyslipidaemia medication. Diabetologia. 2010;53:2518-25.

76. Mihailescu DV, Vora A, Mazzone T. Lipid effects of endocrine medications. Curr Atheroscler Rep. 2011;13:88-94.

77. Stumvoll M, Nurjhan N, Perriello G, Dailey G, Gerich JE. Metabolic effects of metformin in non-insulin-dependent diabetes mellitus. N Engl J Med. 1995;333:550-4.

78. Zinman B, Wanner C, Lachin JM, et al. Empagliflozin, cardiovascular outcomes, and mortality in type 2 diabetes. $\mathrm{N}$ Engl J Med. 2015;373:2117-28.

79. Heart Protection Study Collaborative Group. MRC/BHF heart protection study of cholesterol lowering with simvastatin in 20,536 high-risk individuals: a randomised placebo-controlled trial. Lancet. 2002;360:7-22.

80. Collins R, Armitage J, Parish S, et al. Effects of cholesterol-lowering with simvastatin on stroke and other major vascular events in 20536 people with cerebrovascular disease or other high-risk conditions. Lancet. 2004;363:757-67.

81. Soran H, Schofield JD, Durrington PN. Cholesterol, not just cardiovascular risk, is important in deciding who should receive statin treatment. Eur Heart J. 2015;36:2975-83.

82. Collins R, Armitage J, Parish S, Sleigh P, Peto R, et al. $\mathrm{MRC} / \mathrm{BHF}$ heart protection study of cholesterol-lowering with simvastatin in 5963 people with diabetes: a randomised placebo-controlled trial. Lancet. 2003;361:2005-16.

83. Preiss D, Seshasai SR, Welsh P, et al. Risk of incident diabetes with intensive-dose compared with moderate-dose statin therapy: a meta-analysis. JAMA. 2011;305:2556-64. 
84. Bayturan O, Kapadia S, Nicholls SJ, et al. Clinical predictors of plaque progression despite very low levels of low-density lipoprotein cholesterol. J Am Coll Cardiol. 2010;55:2736-42.

85. Sattar N, Preiss D, Murray HM, et al. Statins and risk of incident diabetes: a collaborative meta-analysis of randomised statin trials. Lancet. 2010;375:735-42.

86. Garcia-Calvo M, Lisnock J, Bull HG, et al. The target of ezetimibe is Niemann-Pick C1-Like 1 (NPC1L1). Proc Natl Acad Sci USA. 2005;102:8132-7.

87. Fonseca VA, Handelsman Y, Staels B. Colesevelam lowers glucose and lipid levels in type 2 diabetes: the clinical evidence. Diabetes Obes Metab. 2010;12:384-92.

88. Garg A, Grundy SM. Cholestyramine therapy for dyslipidemia in non-insulin-dependent diabetes mellitus. A short-term, double-blind, crossover trial. Ann Intern Med. 1994;121:416-22.

89. Wierzbicki AS, Hardman TC, Viljoen A. New lipid-lowering drugs: an update. Int J Clin Pract. 2012;66:270-80.

90. Sattar N, Preiss D, Robinson JG, et al. Lipid-lowering efficacy of the PCSK9 inhibitor evolocumab (AMG 145) in patients with type 2 diabetes: a meta-analysis of individual patient data. Lancet Diabetes Endocrinol. 2016. doi:10. 1016/S2213-8587(16)00003-6

91. Tavori H, Giunzioni I, Fazio S. PCSK9 inhibition to reduce cardiovascular disease risk: recent findings from the biology of PCSK9. Curr Opin Endocrinol Diabetes Obes. 2015;22:126-32.

92. The ACCORD Study Group, Ginsberg HN, Elam $\mathrm{MB}$, et al. Effects of combination lipid therapy in type 2 diabetes mellitus. $\mathrm{N}$ Engl $\mathrm{J}$ Med. 2010;362:1563-74.

93. Wierzbicki AS. Fibrates: no ACCORD on their use in the treatment of dyslipidaemia. Curr Opin Lipidol. 2010;21:352-8.

94. Birjmohun RS, Hutten BA, Kastelein JJ, Stroes ES. Efficacy and safety of high-density lipoprotein cholesterol-increasing compounds: a meta-analysis of randomized controlled trials. J Am Coll Cardiol. 2005;45:185-97.

95. Keech A, Simes RJ, Barter P, et al. Effects of long-term fenofibrate therapy on cardiovascular events in 9795 people with type 2 diabetes mellitus (the FIELD study): randomised controlled trial. Lancet. 2005;366:1849-61.
96. Schofield JD, Liu Y, France MW, Sandle L, Soran H. A review of paradoxical HDL-C responses to fenofibrate, illustrated by a case report. J Clin Lipidol. 2014;8:455-9.

97. Hegele RA, Ginsberg HN, Chapman MJ, et al. The polygenic nature of hypertriglyceridaemia: implications for definition, diagnosis, and management. Lancet Diabetes Endocrinol. 2014;2:655-66.

98. Marchioli R, Barzi F, Bomba E, et al. Early protection against sudden death by $n-3$ polyunsaturated fatty acids after myocardial infarction: time-course analysis of the results of the Gruppo Italiano per lo Studio della Sopravvivenza nell'Infarto Miocardico (GISSI)-Prevenzione. Circulation. 2002;105: 1897-903.

99. Harris WS, Bulchandani D. Why do omega-3 fatty acids lower serum triglycerides? Curr Opin Lipidol. 2006;17:387-93.

100. The ORIGIN Trial Investigators, Bosch J, Gerstein $\mathrm{HC}$, et al. n-3 fatty acids and cardiovascular outcomes in patients with dysglycemia. N Engl J Med. 2012;367:309-18.

101. Harris WS, Miller M, Tighe AP, Davidson MH, Schaefer EJ. Omega-3 fatty acids and coronary heart disease risk: clinical and mechanistic perspectives. Atherosclerosis. 2008;197:12-24.

102. Joshi SR. Saroglitazar for the treatment of dyslipidemia in diabetic patients. Expert Opin Pharmacother. 2015;16:597-606.

103. Epidemiology of Diabetes Interventions and Complications (EDIC) Research Group. Effect of intensive diabetes treatment on carotid artery wall thickness in the epidemiology of diabetes interventions and complications. Diabetes. 1999;48:383-390.

104. Haffner SM, Lehto S, Ronnemaa T, Pyorala K, Laakso M. Mortality from coronary heart disease in subjects with type 2 diabetes and in nondiabetic subjects with and without prior myocardial infarction. $\mathrm{N}$ Engl $\mathrm{J}$ Med. 1998;339:229-34.

105. Diabetes Control and Complications Trial (DCCT)/Epidemiology of Diabetes Interventions and Complications (EDIC) Study Research Group. Intensive diabetes treatment and cardiovascular outcomes in type 1 diabetes: The DCCT/EDIC study 30-year follow-up. Diabetes Care. 2016. doi:10.2337/dc15-1990

106. JBS3 Board. Joint British Societies' consensus recommendations for the prevention of 
cardiovascular disease (JBS3). Heart. 2014;100(Suppl 2):ii1-67.

107. Perk J, De Backer G, Gohlke H, et al. European guidelines on cardiovascular disease prevention in clinical practice (version 2012): the fifth joint task force of the european society of cardiology and other societies on cardiovascular disease prevention in clinical practice (constituted by representatives of nine societies and by invited experts). Eur J Prev Cardiol. 2012;19:585-667.

108. Gyberg V, De Bacquer D, De Backer G, et al. Patients with coronary artery disease and diabetes need improved management: a report from the EUROASPIRE IV survey: a registry from the EuroObservational Research Programme of the European Society of Cardiology. Cardiovasc Diabetol. 2015;14:133.

109. Yudkin JS, Richter B, Gale EA. Intensified glucose lowering in type 2 diabetes: time for a reappraisal. Diabetologia. 2010;53:2079-85.

110. American Diabetes Association. (8) Cardiovascular disease and risk management. Diabetes Care. 2015;38(Suppl):S49-57.

111. Stone NJ, Robinson JG, Lichtenstein AH, et al. 2013 ACC/AHA guideline on the treatment of blood cholesterol to reduce atherosclerotic cardiovascular risk in adults: a report of the American College of Cardiology/American Heart Association Task Force on Practice Guidelines. Circulation. 2014;129:S1-45.

112. European Association for Cardiovascular Prevention \& Rehabilitation, Reiner Z, Catapano $\mathrm{AL}$, et al. ESC/EAS guidelines for the management of dyslipidaemias: the task force for the management of dyslipidaemias of the European Society of Cardiology (ESC) and the European Atherosclerosis Society (EAS). Eur Heart J. 2011;32:1769-818.

113. National Institute for Health and Care Excellence. Lipid modification: cardiovascular risk assessment and the modification of blood lipids for the primary and secondary prevention of cardiovascular disease. London: NICE. 2014.

114. Wulffele MG, Kooy A, de Zeeuw D, Stehouwer CD, Gansevoort RT. The effect of metformin on blood pressure, plasma cholesterol and triglycerides in type 2 diabetes mellitus: a systematic review. J Intern Med. 2004;256:1-14.

115. Buse JB, Tan MH, Prince MJ, Erickson PP. The effects of oral anti-hyperglycaemic medications on serum lipid profiles in patients with type 2 diabetes. Diabetes Obes Metab. 2004;6:133-56.
116. Monami M, Vitale V, Ambrosio ML, et al. Effects on lipid profile of dipeptidyl peptidase 4 inhibitors, pioglitazone, acarbose, and sulfonylureas: meta-analysis of placebo-controlled trials. Adv Ther. 2012;29:736-46.

117. Araki T, Emoto M, Konishi T, et al. Glimepiride increases high-density lipoprotein cholesterol via increasing adiponectin levels in type 2 diabetes mellitus. Metabolism. 2009;58:143-8.

118. Dormandy JA, Charbonnel B, Eckland DJ, et al. Secondary prevention of macrovascular events in patients with type 2 diabetes in the PROactive Study (PROspective pioglitAzone Clinical Trial In macroVascular Events): a randomised controlled trial. Lancet. 2005;366:1279-89.

119. Azimova K, San Juan Z, Mukherjee D. Cardiovascular safety profile of currently available diabetic drugs. Ochsner J. 2014;14:616-32.

120. Siahmansur TJ, Schofield JD, Azmi S, et al. Unintended positive and negative effects of drugs on lipoproteins. Curr Opin Lipidol. 2015;26:325-37.

121. Lavalle-Gonzalez FJ, Januszewicz A, Davidson J, et al. Efficacy and safety of canagliflozin compared with placebo and sitagliptin in patients with type 2 diabetes on background metformin monotherapy: a randomised trial. Diabetologia. 2013;56:2582-92.

122. Boland CL, DeGeeter M, Nuzum DS, Tzefos $M$. Evaluating second-line treatment options for type 2 diabetes: focus on secondary effects of GLP-1 agonists and DPP-4 inhibitors. Ann Pharmacother. 2013;47:490-505.

123. Matikainen N, Manttari S, Schweizer A, et al. Vildagliptin therapy reduces postprandial intestinal triglyceride-rich lipoprotein particles in patients with type 2 diabetes. Diabetologia. 2006;49:2049-57.

124. Zinman B, Ahren B, Neubacher D, et al. Efficacy and cardiovascular safety of linagliptin as an add-on to insulin in type 2 diabetes: a pooled comprehensive post hoc analysis. Can J Diabetes. 2016;40:50-7.

125. Bailey CJ, Gross JL, Pieters A, Bastien A, List JF. Effect of dapagliflozin in patients with type 2 diabetes who have inadequate glycaemic control with metformin: a randomised, double-blind, placebo-controlled trial. Lancet. 2010;375:2223-33. 
126. Ptaszynska A, Hardy E, Johnsson E, Parikh S, List J. Effects of dapagliflozin on cardiovascular risk factors. Postgrad Med. 2013;125:181-9.

127. Forst T, Guthrie R, Goldenberg R, et al. Efficacy and safety of canagliflozin over 52 weeks in patients with type 2 diabetes on background metformin and pioglitazone. Diabetes Obes Metab. 2014;16:467-77.

128. Roden M, Weng J, Eilbracht J, et al. Empagliflozin monotherapy with sitagliptin as an active comparator in patients with type 2 diabetes: a randomised, double-blind, placebo-controlled, phase 3 trial. Lancet Diabetes Endocrinol. 2013;1:208-19.

129. Schwartz EA, Koska J, Mullin MP, , et al. Exenatide suppresses postprandial elevations in lipids and lipoproteins in individuals with impaired glucose tolerance and recent onset type 2 diabetes mellitus. Atherosclerosis. 2010;212:217-22.

130. Vilsboll T, Zdravkovic M, Le-Thi $\mathrm{T}$, et al. Liraglutide, a long-acting human glucagon-like peptide-1 analog, given as monotherapy significantly improves glycemic control and lowers body weight without risk of hypoglycemia in patients with type 2 diabetes. Diabetes Care. 2007;30:1608-10.

131. Hermansen K, Baekdal TA, During $M$, et al. Liraglutide suppresses postprandial triglyceride and apolipoprotein B48 elevations after a fat-rich meal in patients with type 2 diabetes: a randomized, double-blind, placebo-controlled, cross-over trial. Diabetes Obes Metab. 2013;15:1040-8. 